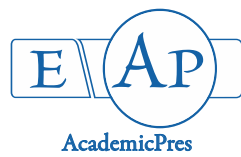

\title{
Prevalence of Increased Serum Urea and Creatinine Levels in Dogs
}

\author{
Ukamaka U. EZE ${ }^{1}$, Ikenna O. EZEH ${ }^{2}$, Ifeanyi G. EKE ${ }^{3}$, \\ Onyinyechukwu A. AGINA ${ }^{4 *}$, Abuchi EGWUONWU ${ }^{1}$, \\ Ekene V. EZENDUKA ${ }^{5}$, Boniface M. ANENE ${ }^{1}$ \\ ${ }^{1}$ University of Nigeria, Faculty of Veterinary Medicine, Department of Veterinary Medicine, Nsukka, Enugu State, \\ Nigeria; ukamakauchenna@unn.edu.ng;egwuonwuabuchi@gmail.com; boniface.anene@unn.edu.ng \\ ${ }^{2}$ University of Nigeria, Faculty of Veterinary Medicine, Department of Veterinary Parasitology and Entomology, Nsukka, Enugu State, \\ Nigeria; ikenna.ezeh@unn.edu.ng \\ ${ }^{3}$ University of Nigeria, Faculty of Veterinary Medicine, Department of Veterinary Physiology, Pharmacology and Biochemistry, Nsukka, Enugu \\ State, Nigeria; ifeanyi.eke@unn.edu.ng \\ ${ }^{4}$ University of Nigeria, Faculty of Veterinary Medicine, Department of Veterinary Pathology and Microbiology, Nsukka, Enugu State, Nigeria; \\ onyinye.noel@unn.edu.ng (corresponding author) \\ ${ }^{5}$ University of Nigeria, Faculty of Veterinary Medicine, Department of Veterinary Public Health and Preventive Medicine, Nsukka, Enugu State, \\ Nigeria; ekene.ezenduka@unn.edu.ng
}

\begin{abstract}
The causes of kidney dysfunction could be related to damages to the glomeruli, nephron, tubules, interstitial tissues and renal blood vessels. The aim of this study was to determine the prevalence of increased levels of serum urea and serum creatinine in dogs presented at the University of Nigeria Veterinary Teaching Hospital (UNVTH). A kidney function test was conducted in dogs for a six-month period (January - June) using kidney function biomarkers (creatinine and urea). A total of 45 dogs were examined. For each dog presented, two milliliters of blood were collected from the cephalic vein for serum biochemistry determinations. Data obtained from this study were analyzed using descriptive statistics. CHI square was used to calculate the strength of association between increased levels of serum urea and creatinine, and sex, age and breed. The prevalence of increased level of serum urea was $71.1 \%$ while that of increased level of serum creatinine was $8.9 \%$. There were no significant association between increases in serum creatinine or serum urea, and sex, age and breed. The prevalence of acute kidney injury was $8.9 \%$. There was no significant association between acute kidney injury (AKI) and sex, age and breed but the risk of having AKI in older dogs were higher if dehydrated and if there was an obstruction to urinary outflow. The results of this study have shown that a greater number of dogs presented at UNVTH suffered from mild loss of kidney function which was not the reason for their presentation at UNVTH. Therefore, routine kidney function tests should be conducted especially on severely sick dogs, as this will help in choice of the drugs.
\end{abstract}

Keywords: creatinine; dogs; kidneys; urea; veterinary hospital

\section{Introduction}

Kidneys are palpable organs that are located in the retroperitoneal space of the abdominal cavity (Wedro, 2018). They are involved in formation of urine, filtering waste products (urea, creatinine and other non-protein nitrogenous compounds) from the blood, regulation of water balance, glomerular filtration, tubular re-absorption, tubular secretion, regulation of blood pressure, synthesis of vitamin $\mathrm{D}$ and production of erythropoietin required in red blood cell, production (Hoffman, 2012; Wedro, 2018). The functional unit of the kidney is the nephron, which is made up of glomerulus, Bowman's capsule, proximal tubule, loop of Henle, distal tubule, and collecting duct (Pocock, 2006). Each kidney contains about 300 - 400,000 nephrons in the dog. The kidney receives about $22 \%$ of cardiac output 
(Eisenbrandt et al., 1979). It is possible to lose as much as 70 - $90 \%$ of kidney functions without experiencing any clinical signs and symptoms (Hoffman, 2012). The study of the kidney function is known as renal physiology while the study of the medical specialty of kidney disease is referred to nephrology. Diseases of the kidney are diverse, but individuals with kidney disease frequently display characteristic clinical features.

Common pathological conditions involving the kidney includes the nephritis and nephrotic syndromes, nephrosis (hemoglobinuric, myoglobinuric and glycogen nephrosis), glomerulonephritis, interstitial nephritis, renal cysts, acute kidney injury, chronic kidney disease (nephrosclerosis), hydronephrosis, renal neoplasms, urinary tract infection, kidney stones (Kumar et al., 2014). Symptoms of kidney failure which are attributed to build-up of waste products include weakness, shortness of breath, lethargy, abnormal heart rhythms, and sudden death (Tierney et al., 2004; Weisberg, 2008).

Pyelonephritis is an infection of kidney pelvis caused by bacteria infection. This occurs as a result of extension of bacterial infection from the lower urinary tract up to the kidney. A predisposing influence to the development of pyelonephritis is stasis of urine in the lower urinary tract as a result of uroliths or prostate hypertrophy (Ihedioha and Chineme, 2004). Glomerulonephritis is inflammation of the glomerulus and associated renal tubules and interstitial tissues. It is caused by overactive immune system whereby there is production of autoantibodies against the glomerular basement membrane. It actually involves deposition of immune complexes within the glomeruli. This leads to kidney damage and inflammation. Kidney stones (nephrolithiasis) are concretions formed in the urinary tract and are made up of salts of inorganic and organic acids. They lead to the blocking of the urinary passages. These stones are commonly found in the bladder and may also occur in the renal pelvis, ureter or male urethra. Wherever these stones occur, they cause mechanical irritation. Lodgment of the stones in the ureter cause ureteral colic. It is worthy to note that kidneys do not regenerate new nephrons, therefore, injury, auto-immune disease, or aging process cause gradual decrease in the numbers of functioning nephron (Ihedioha and Chineme, 2004).

Renal dysfunction could be classified based on pre-renal, renal and post-renal azotemia. Pre-renal azotemia is caused by a decrease in blood flow to the kidneys. It can occur following hemorrhage, low blood volume, low blood pressure, heart failure (leading to cardio-renal syndrome), liver cirrhosis and local changes to the blood vessels supplying the kidney. The latter include renal artery stenosis, or the narrowing of the renal artery, and renal vein thrombosis (formation of a blood clot in the renal vein that drains blood from the kidney) (Kumar et al., 2005). Renal azotemia typically leads to uremia. Causes of renal azotemia include renal failure, glomerulonephritis, acute tubular necrosis, renal hypoxia and ischemia (Goljan et al., 2007). Post-renal azotemia occurs due to blockage of urine flow due to urinary tract obstruction in an area below the kidneys. It could be caused by congenital abnormalities such as vesicoureteral reflux, blockage of urethra by uroliths or tumour at the neck of the bladder and urethra (Kumar et al., 2005; Edward et al., 2007).

Renal damage could be described as either acute or chronic. Acute renal damage is an abrupt decline in renal excretory function characterized by a reversible increase in blood circulation of creatinine and blood urea nitrogen due to the inability of the kidney to regulate fluid and electrolyte homeostasis (Bellomo et al., 2012). There is also a rapidly progressively loss of renal function resulting in retention of uremic toxins, as well as fluid acid-base and electrolyte imbalances (Cowgill et al., 2005; Ronco et al., 2012). It is generally characterized by oligouria (Klahr et al., 1998). Acute renal damage affects some organs of the body and it is said to be a multi-system disease (Francey et al., 2002). There is a sudden onset of renal parenchyma injury most typically characterized by generalized failure of kidneys to meet excretory, metabolic, and endocrine demands of the body (Mehta, 2007). This condition is determined by checking the level of serum creatinine and urea since it reflects the level of glomerular filtration rate due to a number of renal and non-renal influences (Star, 1998). Acute renal damage may lead to a number of complications, including metabolic acidosis, high potassium levels, uremia, changes in body fluid balance, and effects on other organs system, including death. Dogs that have experienced acute renal damage may have an increased risk of chronic kidney disease in the future (Kellum et al., 2004). Causes of acute renal damage could also be categorized into ischemic causes (e.g. hypotension) and drugs like non-steroidal antiinflammatory drugs. ACE Inhibitors induce ischemia which usually causes reversible injury, infectious causes (e.g. leptospirosis, canine distemper etc.) and nephrotoxic causes (e.g. ethylene glycol, gentamycin) (Segev et al., 2007; Segev et al., 2008). Acute renal damage is diagnosed based on characteristic laboratory findings, such as elevated blood urea nitrogen and creatinine, or inability of the kidney to produce sufficient amount of urine (Holley, 2009).

Chronic kidney damage (CKD) is the most common renal disease in dogs and it's said to be a primary renal failure that has occurred for a period usually months to years (Polzin, 2011). Chronic kidney damage (CKD) irrespective of the cause is characterized by irreparable renal structural injury and reduction in renal mass (Lulich et al., 1992). It occurs in dogs of all ages but is more considered as a disease of older animals and the incidence increase with age (Lulich et al., 1992). It is manifested by abnormal albumin excretion or decreased kidney function, quantified measured or estimated glomerular filtration rate (GFR), which persists for more than 3 months (Levey et al., 2005). This condition develops slowly and, initially, show few symptoms. It is a long term consequence of irreversible acute disease or part of a disease progression. Chronic kidney damage develops clinically by progressive irreversible intra renal lesions and loss of renal functions. It has been reported that CKD is a major cause of morbidity and death in dogs and, given that it is typically diagnosed relatively late in the cause of the disease, dogs with advanced changes represent only a fraction of all dogs with chronic kidney disease (Robertson, 1986). 
342

In the University of Nigeria Veterinary Teaching Hospital (UNVTH), the assessment of kidney function in dogs presented for routine checkup, treatment and vaccination is not a norm. This assessment could help to assure that an early diagnosis of acute renal ischemia, vasoconstriction, reduced glomerular filtration rate (GFR), and nephrotoxic insults be made prior to the occurrence of tubular dysfunction, thus providing the potential to prevent progression to established acute kidney damage (AKD). The assessment of renal function can also inform the choice of drugs to be used in treatment of a particular disease. Therefore, this study was performed to screen dogs presented at UNVTH for evidence of renal damage/injury.

\section{Materials and Methods}

Study area

The study was performed in the University of Nigeria Veterinary Teaching Hospital, located in Enugu State, Nigeria. Nsukka is located at the Northern part of Enugu State, Nigeria. It is situated within the derived savanna belt of the state between latitude $5^{\circ} 50^{\prime}$ and $7^{\circ} 00^{\prime}$ North and longitude $6^{\circ} 50^{\prime}$ and $7^{\circ} 54^{\prime}$. Nsukka has a yearly rainfall of $119.5 \mathrm{~mm}$ (FMANR, 1999).

\section{Sample size and blood sample collection}

A total of forty-five (45) dogs of varying sexes, breeds and ages were studied for 6 months (January - June, 2017). These were dogs presented for treatment, routine vaccination and checkup at UNVTH. The sampling was done once a week for 6 months. On presentation, identification of dogs was made (Name, sex, age, weight, and breed). Also, the history, tentative or confirmatory diagnosis and the treatment protocols of the cases were recorded. On presentation at the Veterinary Teaching Hospital, two milliliters of blood were collected from each dog for serum biochemistry determinations. Sera were harvested into vacutainers following centrifugation of $2 \mathrm{mls}$ clotted blood samples using a low speed table centrifuge (Centromix, P. Selecta; Barcelona), at $3000 \mathrm{~g}$ for 15 minutes. The serum biochemistry determinations were performed immediately. The samples were not stored.

\section{Serum biochemistry determinations}

The serum biochemistry determinations were done using commercial test kits; Randox tests kits (Randox, UK) and a digital colorimeter (Lab-tech, India). The serum urea was determined by the Berthelot-Searcy method (Fawcett and Scott, 1960), while the serum creatinine was determined by the modified Jaffe method (Blass et al., 1974).

\section{Statistical analysis}

Results were analysed by descriptive statistics and presented as percentages using tables. GraphPad prism statistical package version 5.2 for Windows (GraphPad Software, La Jolla California USA, www.graphpad.com) was used to analyse generated data, where Chi square test was used to determine association between categorical variables. Significance was accepted at $\mathrm{p}<0.05$.

\section{Results}

Out of 45 dogs examined, 25 (55.6\%) were females $(68.9 \%)$ and $20(44.4 \%)$ were males. A total of $22(48.9 \%)$ were between 0 - 6 months of age, $10(22.2 \%)$ were between 7 - 12 months of age while $13(28.9 \%)$ were greater than 12 months of age. A total number of $14(31.1 \%)$ were exotic breeds while 31 (68.9\%) were the indigenous breed of dogs. Dogs that showed concurrent increases in their serum urea and creatinine values were $4(8.9 \%)$ (Table 1$)$, and they were regarded as dogs with acute kidney injury (AKI). Therefore, the prevalence of acute kidney injury in dogs was $8.9 \%$ (Table 1 ). The males had a higher AKI prevalence of $10 \%$ than females (8\%) (Table 2), but no significant $(p>0.05)$ association between acute kidney injury and sex were observed. Although, dogs of 12 months and above had a higher prevalence (15.4\%) of AKI than 0 - 6 months old dogs $(4.5 \%)$ (Table 3$)$, no significant $(p>0.05)$ association between AKI and age were recorded. The exotic breed of dogs had a higher prevalence of $14.3 \%$ than the Nigerian indigenous breed (6.5\%) (Table 4). Although no significant $(p>0.05)$ association was recorded, the odds of having AKI was 2 times higher in exotic than indigenous breeds of dogs (Table 4).

The overall prevalence of increased serum urea level was 71.1\% (Table 5). The female dogs had a slightly higher prevalence of $72 \%$ than the male dogs (70\%) (Table 6). Dogs of 12 months and above had a higher prevalence of $84.6 \%$ than dogs of 0 - 6 months of age $(63.3 \%$ ) (Table 7$)$. The exotic breed of dogs had a higher urea prevalence rate of $85.7 \%$ than the indigenous breed having $64.5 \%$ (Table 8 ). Dogs whose weight were between $11-15 \mathrm{~kg}$ had a higher prevalence of $100 \%$ than dogs weighing between $26-30 \mathrm{~kg}$ (50\%) (Table 9). There were no significant $(\mathrm{p}>0.05)$ association between increased serum urea level and sex, age, breed and weight respectively (Tables 6, 7, 8 and 9).

The overall prevalence of increased serum creatinine concentration was $8.9 \%$ (Table 5), with the males having a slightly higher prevalence of $10 \%$ than the females $(8 \%)$ (Table 10). Dogs that were 12 months of age and above had a slightly higher prevalence of $61.5 \%$ than dogs between 0 6 months of age (50\%) (Table 11). The exotic breeds had a higher prevalence of $14.3 \%$ than indigenous breed $(6.5 \%$ (Table 12). Dogs weighing between $1-5 \mathrm{~kg}$ had higher prevalence rate of $50 \%$ when compared to dogs whose weight were between 6 - $10 \mathrm{~kg}(7.1 \%)$ (Table 13). There were no significant $(\mathrm{p}>0.05)$ association between increased serum creatinine level and sex, age, breed and weight respectively (Tables 10, 11, 12 and 13).

Dogs with acute kidney damage had mean serum creatinine value of $3.17 \pm 1.09 \mathrm{mg} / \mathrm{dl}$ and mean serum urea value of $23.94 \pm 2.98 \mathrm{mg} / \mathrm{dl}$ (Table 14). The dogs with increased urea concentration only, had $39.94 \pm 3.34 \mathrm{mg} / \mathrm{dl}$ as their mean urea value (Table 15) while those with increased creatinine concentration only, had $3.17 \pm 1.09$ $\mathrm{mg} / \mathrm{dl}$ as their mean creatinine value (Table 16). 
Table 1. The prevalence of concurrent increases in serum urea and creatinine (acute kidney damage) in dogs presented at veterinary teaching hospital, University of Nigeria, Nsukka (January - June, 2017)

\begin{tabular}{ccccc} 
Serum biochemistry parameters & No. of dogs sampled & No. of dogs with values higher than reference range & Prevalence (\%) \\
\hline Urea and creatinine & 45 & 4 & 8.9 \\
\hline
\end{tabular}

Table 2. Sex distribution of acute kidney damage of dogs presented at the veterinary teaching hospital, University of Nigeria, Nsukka (January - June, 2017)

\begin{tabular}{ccccccc}
\hline Sex & Number sampled & AKD & Prevalence $(\%)$ & Chi-Square & Odds ratio & P-value \\
\hline Females & 25 & 2 & 8 & 0.055 & 0.783 & 0.815 \\
Males & 20 & 2 & 10 & & & \\
Total & 45 & 4 & 8.9 & & & \\
\hline
\end{tabular}

Table 3. Age distribution of acute kidney damage (AKD) in dogs presented at the veterinary teaching hospital, University of Nigeria, Nsukka (January -June, 2017)

\begin{tabular}{cccccc}
\hline Age & Number sampled & AKD & Prevalence (\%) & Chi-Square & P-value \\
\hline 0 - 6 months & 22 & 1 & 21 & 1.205 & 0.547 \\
$7-12$ months & 10 & 1 & 9 & & \\
$>12$ months & 13 & 3 & 11 & & \\
Total & 45 & 4 & 8.9 & & \\
\hline
\end{tabular}

Table 4. Breed distribution of acute kidney damage (AKD) in dogs presented at the veterinary teaching hospital, University of Nigeria, Nsukka (January - June 2017)

\begin{tabular}{ccccccc}
\hline Breed & Number sampled & AKD & Prevalence $(\%)$ & Chi-Square & Odds ratio & P-value \\
\hline Exotic & 14 & 2 & 14.3 & 0.731 & 2.417 & 0.393 \\
Indigenous & 31 & 2 & 6.5 & & & \\
Total & 45 & 32 & 71.1 & & & \\
\hline
\end{tabular}

Table 5. The prevalence of increased serum urea and creatinine in dogs presented at veterinary teaching hospital, University of Nigeria, Nsukka (January - June, 2017)

\begin{tabular}{cccc}
\hline Serum biochemistry parameters & No. of dogs sampled & $\begin{array}{c}\text { No. of dogs with values higher than } \\
\text { reference range }\end{array}$ & Prevalence (\%) \\
\hline Urea & 45 & 32 & 71.1 \\
Serum creatinine & 45 & 4 & 8.9 \\
Total & 45 & 36 & 80 \\
\hline
\end{tabular}

Table 6. Sex distribution of increased serum urea values of dogs presented at the veterinary teaching hospital, University of Nigeria, Nsukka, (January - June, 2017)

\begin{tabular}{cccccc}
\hline Sex & Number sampled & $\begin{array}{c}\text { Number with high urea } \\
\text { values }\end{array}$ & $\begin{array}{c}\text { Prevalence } \\
(\%)\end{array}$ & Chi-Square & P-value \\
\hline Females & 25 & 18 & 72 & 0.02074 & 0.8855 \\
Males & 20 & 14 & 70 & & \\
Total & 45 & 32 & 71.1 & & \\
\hline
\end{tabular}

Table 7. Age distribution of increased serum urea concentration among dogs presented at the veterinary teaching hospital, University of Nigeria, Nsukka (January - June, 2017)

\begin{tabular}{cccccc}
\hline Age & Number sampled & $\begin{array}{c}\text { Number with high urea } \\
\text { values }\end{array}$ & $\begin{array}{c}\text { Prevalence } \\
(\%)\end{array}$ & Chi-Square & P-value \\
\hline $0-6$ months & 22 & 14 & 63.6 & 1.758 & 0.4151 \\
$7-12$ months & 10 & 7 & 70 & & \\
$>12$ months & 13 & 11 & 84.6 & & \\
Total & 45 & 32 & 71.1 & & \\
\hline
\end{tabular}

Table 8. Breed distribution of increased serum urea concentration among dogs presented at the veterinary teaching hospital, University of Nigeria, Nsukka (January - June, 2017)

\begin{tabular}{ccccc}
\hline Breed & Number sampled & Number with high urea values & $\begin{array}{c}\text { Prevalence } \\
(\%)\end{array}$ & P-value \\
\hline Exotic & 14 & 12 & 85.7 & 0.1780 \\
Indigenous & 31 & 20 & 64.5 & \\
Total & 45 & 32 & 71.1 & \\
\hline
\end{tabular}


344

Table 9. Distribution of increased serum urea concentration according to weight among dogs presented at the veterinary teaching hospital, University of Nigeria, Nsukka (January - June, 2017)

\begin{tabular}{cccccc}
\hline Weight $(\mathrm{kg})$ & No. of dogs sampled & No. of dogs with high urea values & Prevalence $(\%)$ & Chi-Square & P-value \\
\hline $1-5$ & 2 & 1 & 50 & 9.680 & 0.2075 \\
$6-10$ & 14 & 9 & 64.3 & \\
$11-15$ & 7 & 7 & 100 & \\
$16-20$ & 8 & 7 & 87.5 & \\
$21-25$ & 8 & 6 & 75 & \\
$26-30$ & 2 & 1 & 50 & \\
$31-35$ & 1 & 0 & 33.3 & \\
$36-40$ & 3 & 1 & 71.1 & \\
& 45 & 32 & & \\
\hline
\end{tabular}

Table 10. Sex distribution of increased serum creatinine value of dogs presented at the veterinary teaching hospital, University of Nigeria, Nsukka, (January - June 2017)

\begin{tabular}{ccccc}
\hline Sex & Number sampled & No. with high creatinine values & $\begin{array}{c}\text { Prevalence } \\
(\%)\end{array}$ & Chi-Square \\
\hline Females & 25 & 2 & 8 & 0.03595 \\
Males & 20 & 2 & 10 & 0.8496 \\
Total & 45 & 4 & 8.9 & \\
\hline
\end{tabular}

Table 11. Age distribution of increased serum creatinine values among dogs presented at the veterinary teaching hospital, University of Nigeria, Nsukka (January - June, 2017)

\begin{tabular}{cccccc}
\hline Age & Number sampled & No. with high creatinine values & Prevalence $(\%)$ & Chi-Square & P-value \\
\hline $0-6$ months & 22 & 11 & 50 & 0.5435 & 0.7621 \\
$7-12$ months & 10 & 6 & 60 & \\
$>12$ months & 13 & 8 & 61.5 & \\
Total & 45 & 32 & 71.1 & & \\
\hline
\end{tabular}

Table 12. Breed distribution of increased serum creatinine concentration among dogs presented at the veterinary teaching hospital, University of Nigeria, Nsukka (January - June, 2017)

\begin{tabular}{ccccc}
\hline Breed & Number sampled & No. with high creatinine values & Prevalence (\%) & P-value \\
\hline Exotic & 14 & 2 & 14.3 & 0.5776 \\
Indigenous & 31 & 2 & 6.5 & \\
Total & 45 & 4 & 71.1 & \\
\hline
\end{tabular}

Table 13. Distribution of increased serum creatinine values according to weight among dogs presented at the veterinary teaching hospital, University of Nigeria, Nsukka (January - June, 2017)

\begin{tabular}{|c|c|c|c|c|c|}
\hline Weight $(\mathrm{kg})$ & Number sampled & No. of dogs with high creatinine values & Prevalence (\%) & Chi-Square & P-Value \\
\hline $1-5$ & 2 & 1 & 50 & 5.973 & 0.5429 \\
\hline $6-10$ & 14 & 1 & 7.1 & & \\
\hline $11-15$ & 7 & 1 & 14.3 & & \\
\hline $16-20$ & 8 & 0 & 0 & & \\
\hline $21-25$ & 8 & 1 & 12.5 & & \\
\hline $26-30$ & 2 & 0 & 0 & & \\
\hline $31-35$ & 1 & 0 & 0 & & \\
\hline $36-40$ & 3 & 0 & 0 & & \\
\hline Total & 45 & 4 & 8.9 & & \\
\hline
\end{tabular}

Table 14. Some serum biochemistry parameters of dogs with acute kidney damage compared with dogs whose values are within the reference values (January - June, 2017)

\begin{tabular}{cccc}
\hline Serum biochemistry parameters & $\begin{array}{c}\text { Dogs with acute kidney damage } \\
(\mathrm{n}=4)\end{array}$ & $\begin{array}{c}\text { Dogs with values within the reference } \\
\text { values }(\mathrm{n}=9)\end{array}$ & $\begin{array}{c}\text { Reference values } \\
\text { (Lumsden et al., 1979) }\end{array}$ \\
\hline Creatinine $^{*}(\mathrm{mg} / \mathrm{dl})$ & $3.17 \pm 1.09$ & $0.66 \pm 0.02$ & $0.5-1.5$ \\
\hline Urea* $\left.^{*} \mathrm{mg} / \mathrm{dl}\right)$ & $23.94 \pm 2.98$ & $15.55 \pm 0.53$ & $10-20$ \\
\hline
\end{tabular}

Asterisk superscript in a row indicates significant difference $(\mathrm{p}<0.05)$

Table 15. Increased serum urea value of dogs presented at the veterinary teaching hospital, UNN, (January - June 2017)

\begin{tabular}{cccc}
\hline Serum biochemistry parameters & $\begin{array}{c}\text { Dogs with increased serum urea } \\
\text { values }(\mathrm{n}=32)\end{array}$ & $\begin{array}{c}\text { Dogs with values within the reference } \\
\text { values }(\mathrm{n}=9)\end{array}$ & $\begin{array}{c}\text { Reference values } \\
\text { (Lumsden et al., 1979) }\end{array}$ \\
\hline Urea* $(\mathrm{mg} / \mathrm{dl})$ & $39.94 \pm 3.34$ & $15.55 \pm 0.53$ & $10-20$ \\
\hline Asterisk superscript in a row indicates significant difference $(\mathrm{p}<0.05)$ & &
\end{tabular}

Asterisk superscript in a row indicates significant difference $(\mathrm{p}<0.05)$ 
Table 16. Increased serum creatinine values of dogs presented at the veterinary teaching hospital, UNN, (January - June, 2017)

\begin{tabular}{cccc}
\hline Serum biochemistry parameters & $\begin{array}{c}\text { Dogs with increased serum creatinine } \\
\text { values }(\mathrm{n}=4)\end{array}$ & $\begin{array}{c}\text { Dogs with values within the reference } \\
\text { values }(\mathrm{n}=9)\end{array}$ & $\begin{array}{c}\text { Reference values } \\
\text { (Lumsden } \text { et al., 1979) }\end{array}$ \\
\hline Creatinine $(\mathrm{mg} / \mathrm{dl})$ & $3.17 \pm 1.09$ & $0.66 \pm 0.02$ & $0.5-1.5$ \\
\hline Asterisk superscript in a row indicates significant difference $(\mathrm{p}<0.05)$ &
\end{tabular}

\section{Discussion}

The finding of a low prevalence rate of acute kidney injury in this study could be attributed to the fact that serum creatinine and urea are generally insensitive and nonspecific markers for early detection of kidney injury and renal dysfunction (Braun et al., 2003; Defauw et al., 2018). These non-specific bio-markers are only altered when more than $75 \%$ of renal mass has been lost (De loor et al., 2013). Recent studies in developed countries have shown that the urinary immunoglobulin $\mathrm{G}$, urinary $\mathrm{C}$-reactive protein, urinary retinol-binding protein and neutrophil gelatinaseassociated lipocalin are better biomarkers for early detection of acute kidney injury (Defauw et al., 2018; van den Berg et al., 2018). From this study, we observed that age, sex, and breed were not significant predisposing factors to acute kidney injury in dogs. This is not in agreement with previous works on kidney damage that stated that an aged animal is more prone to kidney injury than the young one (Lulich et al., 1992). The finding of age not been a significant factor in acute kidney injury is not completely understood but may be attributed to the small sample size used in this study. Some of the drugs used in routine treatment of dogs such as aminoglycosides (gentamycin) and sulphonamides (sulphadimidine) are nephrotoxic and their effect are exacerbated by dehydration thus causing nephrotoxicity with attendant tubular damage (Singh et al., 2013). Dehydration is one of the major causes of pre-renal azotaemia with intact tubular function (Schrier et al., 2004). If fluid therapy is not instituted in these patients to increase the glomerular filtration rate, there will be sustaining azotemia and the promotion of ischemic renal injury which can end up in renal failure (Polzin, 2005).

The higher prevalence of increased serum urea than serum creatinine levels in dogs in this present study suggests that most of the patients had conditions associated with reduced urinary excretion of urea. These conditions maybe pre-renal disorders caused by dehydration, hypovolemia and decreased cardiac output, and possible post-renal obstruction in the urinary bladder leading to urinary stasis. Other conditions associated with increased serum urea levels include possible increased dietary intake of urea, intestinal haemorrhage following worm infestation or bleeding intestinal ulcers and increased protein catabolism (Schrier et al., 2004. The finding of a higher prevalence of serum urea levels in dogs 12 months and above, suggest that as a dog ages, the probability of having the kidneys injured when dehydrated or following urinary stasis, is high (Lulich et al., 1992). The exotic breeds of dogs having higher serum urea prevalence than indigenous breed could be attributed to diet and/or genetic predisposition. The finding of higher urea prevalence in dogs weighing between 11 - $15 \mathrm{~kg}$ than 26 - $30 \mathrm{~kg}$ dogs was not completely understood.
The exotic breed of dogs had higher serum creatinine prevalence than indigenous breed. Although, there were no significant association between breed and acute kidney injury, the risk of having acute kidney injury was two times higher in exotic than indigenous breeds. This could also be attributed to diet and/or genetic predisposition. Dogs weighing between $1-5 \mathrm{~kg}$ had higher creatinine prevalence than dogs whose weights were between $6-10 \mathrm{~kg}$. This observation could be attributed to post-analytical error.

It was observed that all dogs with high serum creatinine levels are the same dogs that had acute kidney injury. This observation further supports that serum creatinine is a better indicator of renal function when compared to serum urea. This is because the quantity of creatinine presented to the kidneys is more constant and is not resorbed by the tubules, whereas urea is reabsorbed (Stockham and Scott, 2008).

\section{Conclusions}

From this study, it can be concluded that the prevalence of acute kidney injury (AKI) was low (8.9\%), and that sex, age, breed and weight were not statistically significant predisposing factors to AKI. But as exotic breeds and older dogs ages and become dehydrated or have urinary stasis due to blockage to urinary outflow from the bladder, they are at greater risk of having their kidneys damaged. The prevalence of increased serum urea level was high (71.1\%) while that of increased serum creatinine was low $(8.9 \%)$ in dogs presented at University of Nigeria Veterinary Teaching. Also, dogs presented at UNVTH may be at risk of having renal disease due to dehydration as a result of parvoviral enteritis, which is a common disease of dogs in Enugu State Nigeria. It was therefore recommended that the dehydration status of sick patients should be determined and nephrotoxic drugs should not be administered in patients at risk of renal injury.

Kidney function tests should be included as routine tests in critically sick and dehydrated dogs. Aminoglycosides and sulphonamides should be used with caution. Also, a larger sample size should be considered while carrying out further studies on acute kidney damage in dogs in Nigeria.

\section{Acknowledgements}

The authors wish to thank the staff and clinical students at the University of Nigeria Veterinary Teaching hospital for their help and support during blood sample collection from clinically healthy dogs.

\section{Conflict of Interest}

The authors declare that there are no conflicts of interest related to this article. 
346

\section{References}

Bellomo R, Kellum JA, Ronco C (2012). Acute kidney injury. Lancet 380(9843):756-766.

Blass KG, Thiebert RJ, Lam LK (1974). A study of the mechanism of the Jaffe reaction. Clinical Chemistry and Laboratory Medicine 12(7):336343.

Braun JP, Lefebvre HP, Watson AD (2003). Creatinine in the dog: a review. Veterinary Clinical Pathology 32(4):162-179.

KumarV,Abbas AK, Aster JC (2014). Robbins and Cotran pathologic basis of disease. St. Louis, MO.Elsevier Saunders.

Cowgill LD, Francey T (2005). Acute uremia. In: Ettinger SJ, Feidman EC (Eds). Textbook of veterinary internal medicine, $6^{\text {th }}$ edition. Philadelphia,Saunders WB pp 1731-1751.

De loor J, Daminet S, Smets P, Maddens B, Meyer E (2018). Urinary biomarkers for acute kidney injury in dogs. Journal of Veterinary Internal Medicine 27(5):998-1010.

Defauw P, Daminet S, Leisewitz AL, Goddard A, Paepe D, Duchateau L, Schoeman JP (2018). Renal azotemia and associated clinical and laboratory findings in dogs with Babesia rossi infection. The Veterinary Journal 260:22-29.

Eisenbrandt DL, Phemister RD (1979). Postnatal development of the canine kidney: quantitative and qualitative morphology. American Journal of Anatomy 154(2):179-193.

Fawcett JK, Scott JE (1960). A rapid and precise method for the determination of urea. Journal of Clinical Pathology 13(2):156-159.

Federal Ministry of Agriculture and Natural Resources (FMANR) (1999) Geographical data. FMNAR, Enugu, Nigeria.

Francey T, Cowgill LD (2002). Use of hemodialysis for the treatment of acute renal failure (AFR) in the dog: 124 cases (1990-2001). Journal of Veterinary Internal Medicine 16:352.

Goljan EF (2007). Rapid review pathology (2nd edition). Mosby.

Hoffman P, Keller F (2012). Increased major bleeding risk in patients with kidney dysfunction receiving enoxaparin: a meta-analysis. European Journal ofClinical Pharmacology 68(5):757-765.

HolleyJL (2009). Clinical approach to the diagnosis of acute renal failure. In: Greenberg A, Cheung AK (Eds). Primer on kidney diseases. $5^{\text {th }}$ edition Philadelphia, Pa. National Kidney Foundation.

Ihedioha JI, Chineme CN (2004). Fundamentals of systemic veterinary pathology, Volume 1. Great AP Express Publishers Limited Nigeria.

Kellum JA, Bellomo R, Ronco C (2004). Defining acute renal failure: physiologic principles. Intensive Care Medicine 30(1):33-37.

Levey AS, Eckardt KU, Tsukamoto Y, Levin A, Coresh J, Rossert J, ... Eknoyan G (2005). Definition and classification of chronic kidney disease: a position statement from kidney disease: Improving global outcome (KDIGO). Kidney International 67(6):2089-2100.

Lulich J, Osborne CA, O’Brien TD, Polzin DJ (1992). Feline renal failure: questions, answers, questions. Compendium Continuing Education for Veterinarian 14:127-152.
Lumsden JH, Mullen K, McSherry BJ (1979). Canine hematology and biochemistry reference values. Canadian Journal of Comparative Medicine 43(2):125-131.

Mehta RL, Kellum JA, Shah SV, Molitoris BA, Ronco C, Warnock DG,Levin A (2007). Acute kidney injury network: report of an initiative to improve outcomes in acute kidney injury. Critical Care 11(2):R31.

Pocock G (2006). Human physiology. Third edition. Oxford University Press, UK.

Polzin DJ, Osborne CA, Ross S (2005). Chronic kidney disease. In: Ettinger SJ, Feldman EC (Eds). Textbook of veterinary internal medicine: Diseases of the dog and cats, Gthed. Stephen JE, Feldman EC (Eds). St. Louis, MO, Oxford, Elsevier Saunders pp 1756-1785.

Polzin DJ (2011). Chronic kidney disease in small animals. Veterinary clinics North America: Small Animal Practice 41:15-30.

Robertson JL (1986). Spontaneous renal disease in dogs. Journal Toxicology and Pathology 14(1):101-108.

Schrier RW, Wang W, Poole B, Mitra A (2004). Acute renal failure: definitions, diagnosis, pathogenesis, and therapy. Journal of Clinical Investigation 114(1):5-14.

Segev G, Kass HP, Francey T, Cowgill LD (2007). A novel clinical scoring system for outcome prediction in dogs with acute kidney injury managed by hemodialysis. Journal of Veterinary Internal Medicine 22(2):301-308.

Singh TB, Rathore SS, Choudhury TA, Shukla VK, Singh DK, Prakash J (2013). Hospital-acquired acute kidney injury in medical, surgical, and intensive care unit: A comparative study. Indian Journal of Nephrology 23(1):24-29.

Star RA (1998). Treatment of acute renal failure. Kidney International 54(6):1817-1831.

Stockham SL, Scott MA (2008). Fundamentals of veterinary clinical pathology. $2^{\text {nd }}$ ed. Blackwell Publishing Iowa, USA.

Tierney LM, McPhee SJ, Papadakis MA (2005). Current medical diagnosis and treatment. $44^{\text {th }}$ edition. McGraw-Hill.

Van den Berg MF, Schoeman JP, Defauw P, Whitehead Z, Breemersch A, Goethals K, ... Meyer E (2018). Assessment of acute kidney injury in canine parvovirus infection: Comparison of kidney injury biomarkers with routine renal functional parameters. The Veterinary Journal 242:814.

KlahrS, MillerSB (1998). Acute oliguria. New England Journal of Medicine 338(10):671-675.

Wedro B (2018). Kidney failure symptoms, signs, stages and treatment. Retrieved 2018 November 7 from www.medicinenet.com.

Weisberg LS (2008). Management of severe hyperkalemia. Critical care Medicine 36(12):3246-3251. 